Symposium on the future of the policy sciences

\title{
Introduction: Generational continuity and change
}

\section{STEVEN R. BROWN}

Department of Political Science, Kent State University, Kent, OH 44242, U.S.A.;

E-mail: sbrown@kent.edu

Socrates postulated that "the States are as the men are; they grow out of human characters" (Plato's Republic, Bk 8), and the same can be said of groups and organizations: they, too, reflect the character of their constituents. Plato and Aristotle were concerned to understand how states change (e.g., from aristocracy to timocracy to meritocracy, or from polity to democracy), and in a penetrating essay located in an obscure psychoanalytic journal, Harold Lasswell (1959) supplemented ancient understandings with the insights of Freud, noting that the stability of the constitution - understood not as a mere document, but as a persistent pattern of conduct - is dependent on continuity in the molding of appropriate forms of personality (including skill sets and conceptual frameworks) that receive sufficient reinforcement to enable them to resist deterioration in transmission from generation to generation. Lasswell went on to suggest that the perpetuation of social forms can be threatened by various factors, including discontinuities and tensions between the older and younger generation. For example, if the rising generation is perceived as veering, however innocently, from established lines of development, the elders may deviate from their own ordinary practices and begin overemphasizing the ideals and standards of "the good old days." This divergence from past practices can be confusing to members of the aspiring generation, often leading them to commit to new directions and eventually dragging institutions with them as they come into their own. ${ }^{1}$

It is for reasons such as these that it is important for a self-conscious movement such as the policy sciences, which has a distinguishing perspective that it seeks to nourish, to take stock of its past and to consider that past in light of its likely affect on the future so as to avoid the aversive possibilities that Plato described. It is in this spirit that in the essay that follows, questions about the future of the policy sciences are raised by Roger Pielke, a member of the Editorial Board, who was trained and influenced in important ways by one of Harold Lasswell's own students, and who therefore looks at the current state of affairs from the standpoint of a third generation that has only read about its progenitors and heard about their exploits second-hand. Using many of the intellectual concepts and principles developed within the policy sciences, Pielke examines the goals of the movement and trends that have preceded current conditions, which he sees as holding the potential for a less than optimal future if steps are not taken to thwart antithetical tendencies.

The challenges contained in Pielke's perspective are critically examined by three other policy scientists (also members of the Editorial Board) at different points in their careers. Richard Wallace is of Pielke's generation and takes exception to many 
of the latter's assertions, as does Rodney Muth, a student of Lasswell who therefore speaks with the authority of the second generation. Pielke's observations receive their warmest reception from David Pelletier, who stands midway between the second and third generations but who enters the discourse from a somewhat oblique angle, having been trained in a different tradition before being attracted to the policy sciences. Pielke is given the opportunity to reply to his commentators, and the entire exchange is lubricated not only by mutual respect but also by the common use of those conceptual tools bequeathed by intellectual predecessors. ${ }^{2}$

Preserving a heritage is tricky business, for success is rarely accomplished by preservation as such - we are not, after all, museum curators standing guard over glass cases - rather, by enriching and developing, which in turn require openness to novel ideas and contested assertions as well as a tolerance for the tensions of selfappraisal. History is strewn with examples of groups, institutions, and civilizations governed by demanding tyrants or by sterile aristocracies unable to reproduce, and still others torn asunder by rivalrous siblings. It is therefore a pleasure to witness these participants reaching across generations and cooperating in a shared pursuit, and we are indebted to them for engaging in this salubrious dialogue on our behalf.

\section{Notes}

1. A recent example is provided by Alexander Waugh (2004), whose great-great-grandfather Alexander was overbearing toward his own son Arthur, who then reacted by spoiling his eldest son Alec, which in turn gave rise to resentment in Alec's brother Evelyn. Evelyn Waugh's neediness led not only to his famed wit and uncommon capacity for expressing it, but also to conditional expressions of affection toward his own son Auberon, who consequently loved his father all the more, giving rise to admiration in young Alex, who named his own son Bron, after his father.

2. It is worth noting in this regard that Lasswell saw Freud's theories as having been anticipated by Plato, who was already aware of oedipal conflicts - i.e., "that in all of us ... there is a lawless wild-beast nature, which peers out in sleep" and commits incestuous crimes (Republic, Bk 9). What impressed Lasswell were not Freud's theories but his methods, and what is likewise noteworthy in the essays to follow is the role that method plays in both dredging up problems and providing leverage for addressing them.

\section{References}

Lasswell, H. D. (1959). 'Political constitution and character,' Psychoanalysis and the Psychoanalytic Review 46(4): 3-18. Reprinted: In H. D. Lasswell and M. S. McDougal, Jurisprudence for a free society, Vol. 1. Dordrecht: Martinus Nijhoff; New Haven, CT: New Haven Press, pp. 685-699.

Waugh, A. (2004). Fathers and Sons: The Autobiography of a Family. London: Telegraph Books. 